\title{
Toward Principles of Construct Clarity: Exploring the Usefulness of Facet Theory in Guiding Conceptualization
}

\author{
Meng Zhang \\ Queensland University of Technology \\ m.zhang@qut.edu.au
}

Guy Gable

Queensland University of Technology

g.gable@qut.edu.au

\author{
Arun Rai \\ Georgia State University \\ arun.rai@eci.gsu.edu
}

\section{Abstract}

Conceptualization in theory development has received limited consideration despite its frequently stressed importance in Information Systems research. This paper focuses on the role of construct clarity in conceptualization, arguing that construct clarity should be considered an essential criterion for evaluating conceptualization and that a focus on construct clarity can advance conceptualization methodology. Drawing from Facet Theory literature, we formulate a set of principles for assessing construct clarity, particularly regarding a construct's relationships to its extant related constructs. Conscious and targeted attention to this criterion can promote a research ecosystem more supportive of knowledge accumulation.

Keywords: Conceptualization; Construct Clarity; Concept Clarity; Concept Formation; Construct Development; Meta-Theoretical Principle; Theoretical Framework; Facet Theory; IT Value; IS Success.

\section{Introduction}

Constructs are invented by researchers to designate conceptual abstractions of phenomena (Kaplan 1964). They are the basic building blocks of theory (Weber 2012). The conceptual meaning of a construct is specified through conceptualization (Schwab 1980). Given the frequently stressed importance of constructs, appropriate conceptualization is vital.

This paper discusses conceptualization in theory development. Conceptualization is differentiated from operationalization wherein relevant empirical measures of a construct are identified. Our discussion focuses primarily on conceptualization. Though conceptualization and operationalization must be consistent, they are usually characterized as separate phases according to their temporal occurrence (e.g., MacKenzie et al. 2011). Most researchers would agree that conceptualization should precede operationalization; that is, the meaning of a construct is determined before associating measures with it ${ }^{1,2}$. Note that, although the terms "construct" and "concept" can be differentiated, for simplicity we treat them as synonymous

\footnotetext{
${ }^{1}$ Alternatively, one might advocate for defining the meaning of a construct according to its empirical measures, the underpinning rationale of which is often called operationalism or operationism. Operationalism, irrespective of its associated advantages, has historically received much criticism, particularly regarding limited generalizability of empirically defined constructs (Cook and Campbell 1979).

2 The meaning of a construct can also be modified subsequent to its operationalization (Schwab 1980). Given that modification of meaning will create a new construct that differs from the original one, there is a need to operationalize the modified construct again. Hence, the logical order from conceptualization to operationalization remains unchanged even when a construct's meaning is modified after operationalization.
} 
throughout this paper; we use both terms because they have been used interchangeably in the literature.

Given the criticality of conceptualization in theory development, how conceptualization can be effectively carried out remains an important research question. Generally, researchers consider two categories of quality criteria relevant to conceptualization - (i) construct clarity and (ii) construct validity. Schwab (1980, pp. 5-6) defined construct validity as "representing the correspondence between a construct (conceptual definition of a variable) and the operational procedure to measure or manipulate that construct." There are widely accepted procedures for establishing construct validity (e.g., MacKenzie et al. 2011; Petter et al. 2007; Straub et al. 2004). Moreover, construct validity pertains mainly to operationalization (Suddaby 2010). This paper focuses discussion on the first category of criteria - construct clarity - that has received relatively less attention in the literature. In particular, we are interested in: how can conceptualization achieve greater construct clarity?

The remainder of this paper is organized as follows. In the subsequent section, we use the example of Information Technology Value to illustrate the importance of construct clarity in conceptualization. We then engage more deeply with a discussion about achieving various aspects of construct clarity in conceptualization. We focus on one critical aspect - clarity in terms of a construct's relationships to extant related constructs. By drawing from Facet Theory literature, we formulate a set of principles and explore how this set of principles might be used to guide conceptualization toward greater construct clarity. We discuss how future research might be informed by these ideas. This paper concludes with a summary and a consideration of limitations.

\section{A Case from the IT Value Research Field}

Information Technology (IT) value often implicitly serves as an "umbrella" notion (Hirsch and Lewin 1999), broadly referring to the various consequences of using IT or Information Systems (IS), and subsuming similar terms such as IT business value (Kohli and Grover 2008; Melville et al. 2004), IS success (DeLone and McLean 1992), and IS effectiveness (Grover et al. 1996).

Few would deny that IT value is among the most important and widely employed concepts in the IS field. Research concerned with the implementation and use of IT often employs IT value as a dependent variable (Shang and Seddon 2002; Burton-J ones and Straub 2006). In practice, senior managers need to know the expected and realized value from IT investments (Hitt et al. 2002; Murphy and Simon 2002).

In the research field of IT value, a plethora of studies addressing related issues have been published over the decades (Schryen 2012; DeLone and McLean 1992). Despite periodic naysayers questioning whether IT generates value (e.g., Carr 2003), most studies report positive (direct or indirect) contribution from IT investment to firms' economic and business performance (e.g., Dedrick et al. 2003; Im et al. 2001; Rai et al. 1997).

Extensive and continuing interest in IT value has generated diverse theoretical and empirical approaches to its study (c.f. Kohli and Grover 2008; Dedrick et al. 2003; DeLone and McLean 1992; 2003). In particular, IT value is investigated at different levels of analysis (e.g., individual level versus organizational level [Chan 2000; Petter et al. 2008]), with various intents (e.g., predicting empirical relationships [Devaraj and Kohli 2003] versus explaining theoretical phenomena [Rai et al. 2002]), or using various data collection methods (e.g., panel data [Hitt et al. 2002] versus perceptual data [Gable et al. 2008]).

Concomitant with this diversity is growing concern with possible incomparability across research findings (e.g., Grover et al. 1996; Seddon et al. 1999); such incomparability can be a potential hindrance to knowledge accumulation ${ }^{3}$ (Melville et al. 2004; Wade and Hulland

\footnotetext{
3 Though several frameworks are proposed to improve comparability across diverse IT value studies through identifying their differentiating aspects such as the type of IT investigated and the level of
} 
2004). One factor that can frustrate comparability is inadequate clarity in IT value conceptualization.

IT value can be selectively emphasized. As argued by Petter et al. (2012), the focus of IT value research can change over time. In the early days of computing when the technology was used primarily as a calculator for computing-intensive tasks, the accuracy of calculation was an important concern for defining IT value. As IT functionality expanded and human-computer interaction became increasingly widespread, other aspects of IT value such as usefulness and user satisfaction came to the fore.

Another variable is the way in which IT is used. Waves of technology innovation can alter how users interact with IT and with each other. For instance, the increasing accessibility of mobile devices can move the virtual workplace from the sole use of an organizational PC to the simultaneous use of multiple platforms; this change can reshape the value dimension of IT (e.g., the capability of synchronizing digital content across multiple platforms becomes more important than ever). Moreover, a collaborative effort by multiple firms to leverage IT can similarly redefine the meaning of IT value (e.g., relational or collaborative benefit in the longer term must be considered) (Kohli and Grover 2008).

Yet, extant IT value dimensions rarely disappear in conjunction with the emergence of new aspects of IT value; thus conceptions tend to accumulate. Although new value dimensions for mobile devices need to be captured, decades-old aspects such as system quality and information quality (DeLone and McLean 1992) may still remain fundamental and relevant for conceptualizing IT value. When new aspects of IT value arise from changing IT or IT use contexts, the onus is on the researcher to consider the continuing relevance of extant dimensions.

Conceptualization is further confused and complicated, as few studies are explicit and precise in articulating their conceptualization of IT value. For example, IT value is labelled variously as "benefits", "perceived value", "impact", and "business value" deriving from IT or IS (DeLone and McLean 2003), while important distinctions such as "who perceives the value", "value for whom", and "what kinds of value are business value" remain unclear (cf. Grover et al. 1996; Seddon et al. 1999).

The example of IT value research suggests merit in paying greater attention to concept clarity in conceptualization. Among possible related issues, this paper centres on general conceptualization "goals". Conceptualization can be better guided and more effective with explicit awareness of goals or criteria for good conceptualization.

To avoid misleading reader expectations, brief clarification of the research scope is necessary. Rather than a comprehensive solution to the methodology of conceptualization, this paper offers exploratory considerations with regard to the qualities of a clear conceptualization.

In particular, we set aside how to conceptualize clearly and instead move up to a metatheoretical level, investigating what a clear conceptualization is. Addressing this metatheoretical question may inform targeted and mindful practice of conceptualization. In other words, a deeper understanding of what strong conceptualization is may help us understand how such conceptualization can be achieved. This paper addresses the first link in this chain of understanding: what are the qualities of a clear conceptualization?

\section{A Focus on Construct Clarity in Conceptualization}

"The need for developing precise concepts [...] cannot be overstated" (Osigweh 1989, p. 579). Clear concepts or constructs can be defined as "robust categories that distil phenomena into sharp distinctions that are comprehensible to a community of researchers" (Suddaby 2010, p. 346). Van de Ven (2007, p. 116) noted "what makes definitions of terms significant is that they

analysis chosen (e.g., Grover et al. 1996; Seddon et al. 1999), these attempts have achieved limited success. 
classify the universe into ways that are critical to a theory; or as Plato said, they 'carve at the joints."' In a 2010 editorial in Academy of Management Review, Suddaby (2010) noted that lack of construct clarity is a common reason that reviewers and editors reject manuscripts. His view on the importance of construct clarity is echoed and amplified in several recent articles (e.g., Klein and Delery 2012; Locke 2012; Skilton 2011; Yaniv 2011).

In the IS discipline, Markus and Saunders (2007, p. v) emphasized construct clarity when outlining the characteristics required in Theory and Review papers submitted to MIS Quarterly. These characteristics include:

- Clear conceptualizations of concepts unique to Information Systems research (e.g., the "IT artefact")

- $\quad$ Clear conceptualizations of concepts relevant to Information Systems practice (i.e., "action levers" or interventions such as prototyping, training, etc.).

Furthermore, Weber (2012) noted that a clearly defined construct is able to delineate the boundary conditions of what phenomena are included and what are not included in a theory. Constructs should be precisely defined, otherwise it is not possible to distinguish to which empirical phenomena the theory can apply and to which it cannot (Weber 2012). An unclear construct with ambiguous meaning will jeopardize construct validity (Schwab 1980).

Suddaby (2010) offered relatively more structured analysis for thinking about construct clarity. He outlined four essential components of construct clarity - (1) definitions, (2) scope conditions, (3) relationships between constructs, and (4) coherence. He suggested a good definition of a construct should achieve three things - it should "effectively capture the essential properties and characteristics of the concept or phenomenon under consideration", "should avoid tautology or circularity", and "should be parsimonious" (Suddaby 2010, p. 347). The scope conditions of a construct need to make clear the contextual conditions under which the construct will or will not apply, specifically with regards to the three general categories of space, time, and values. For relationships between constructs, Suddaby (2010) posited that two kinds of relationships should be clarified: (i) a construct's relationships to other constructs in a nomological network and (ii) a construct's relationships to extant related constructs that share conceptual meaning. The fourth component of construct clarity is coherence; coherence requires that the previous three criteria of construct clarity - definitions, scope conditions, and relationships between constructs - need to be organized in a logically consistent way (Suddaby 2010).

The first two components of construct clarity suggested by Suddaby (2010) - definitions and scope conditions - are relatively well attended to in the methodological literature (e.g., MacKenzie et al. 2011; Nunnally and Bernstein 1994; Schwab 1980; Weber 2012). The last component of coherence, though important, demands a degree of intuitiveness and usually relies on one's capabilities (Suddaby 2010); thus its practice may be less amenable to normative prescriptions. We focus our attention on addressing the third component of construct clarity - clarity in the relationships between constructs, the difficulty of which may be a reason it has not been well addressed.

Suddaby (2010) suggested that clarity in the relationships between constructs requires two separate considerations. First, a construct's relationships to other constructs in a nomological network must be clear. This consideration is widely appreciated. According to Cronbach and Meehl (1955), a nomological network causally relates theoretical constructs to each other, or theoretical constructs to observables. If constructs differ within a nomological network, they are said to be qualitatively distinct. For example, "usefulness", "ease of use", and "intention to use" are distinct because their nomological network has been evidenced by good empirical support (Davis 1989).

Yet, the use of a nomological network cannot address clarity in the second type of relationship: a construct's relationships to extant, related constructs that have developed historically along with the focal construct (Suddaby 2010). This kind of relationship demands a consideration separate from the nomological network, because the meanings of these constructs may, and 
often do, "overlap" or "measure the same thing" to some extent. To demonstrate cumulative knowledge progression, strong conceptualization should specify the relationships of a focal construct with extant constructs that may share conceptual meaning (Suddaby 2010). Because it is unproductive to label a construct differently and assume it to be new, it is critical to ensure a new construct is indeed conceptually distinct from extant related constructs.

Aside from Suddaby (2010), other scholars ${ }^{4}$ similarly noted the importance and difficulty of clarifying the relationships between constructs in achieving construct clarity. Drawing from Osigweh (1989), Van de Ven (2007) summarized two general approaches for defining the meaning of a construct, termed semantic and constitutive definitions. He submitted (Van de Ven 2007, p. 115),

A semantic definition describes the meaning of a term by its similarities and differences with other terms. Reference to synonyms and antonyms, as well as metaphors and analogies are useful heuristics for developing semantic definitions. [...] A constitutive definition describes a term with reference to its component parts. [...] While semantic definitions specify the meaning of a concept by extension (i.e., how it is similar to and different from other concepts at the same level of abstraction), constitutive definitions locate the meaning of a concept by intention (i.e., what component terms comprise the concept at lower levels of abstraction, and what more aggregate terms the concept is a member of at high levels of abstraction).

This comparing and contrasting strategy in defining a construct is also suggested by several other scholars. MacKenzie et al. (2011) recommended that the definition of a construct should specify attributes or characteristics that are common to the focal construct and other similar constructs. Nunnally and Bernstein (1994) argued that defining a construct not only requires the explication of its conceptual domain but also adequately addressing how the construct is different from other constructs.

Previous researches that recommend comparison and contrast for achieving construct clarity do not explicitly offer a systematic approach. Toward such a systematic approach, we consider a set of principles for assessing clarity in a construct's relationships to extant related constructs. We hope these principles may help to increase clarity in conceptualization. Beyond what is discussed, it is also necessary to pay fuller attention to other criteria sets suggested by Suddaby (2010) and others.

\section{Principles for Guiding Conceptualization}

Drawing from Facet Theory literature, we offer a set of principles for exploring construct clarity in conceptualization. These principles are adapted from McGrath (1968, pp. 192 - 197); they describe the relationships between a focal construct and other similar or potentially overlapping constructs. In what follows, we briefly summarize Facet Theory and identify its knowledge contribution to various disciplines and areas, critically assessing its strengths and shortcomings. Next, we direct attention to the imagery of Facet Theory and the logic derived from the imagery.

\subsection{Facet Theory}

In the discipline of Psychology, or more precisely, its sub-discipline Psychometrics, Guttman (1954a; 1954b) proposed Facet Theory (FT) in response to concerns arising from the arbitrariness of definition. Guttman (1971, p. 329) noted,

Definitions are of course arbitrary. [...] One can make words mean what one wishes [...hence,] all that is formally required of a definition is that it be clear: that it enable reliable use of the concept concerned. A more informal, heuristic, desideratum is that it actually influence[s] theorists and researchers to progress in their work.

\footnotetext{
4 We thank the special issue editor for pointing us to this relevant body of literature.
} 
The solution for "reliable use" of a concept offered by Guttman is to put the focal concept together with concepts that share meaning in a definitional framework "to make explicit what the focal concept has in common with the others and how it differs from them" (Guttman 1971, p. 329). The entirety of related concepts is presumed to form a content universe within a domain of investigation.

A core activity in Facet Theory is the construction of a definitional framework (Guttman 1954a; 1954b). To understand what a definitional framework looks like, the notion of a facet remains centrally relevant. According to Guttman and Greenbaum (1998, p. 17, emphasis added),

A facet is a set of attributes (variables) that together represent underlying conceptual and semantic components within a content universe. Shye and Elizur (1994, p. 23) define the facet as a "set that plays the role of a component set of a Cartesian set." In mathematical terminology the word "set" refers to a collection of items or objects. Within a set, objects are called "elements." Facets are proposed by the investigator and are comprised of elements that define the different values logically describing the variations within a facet (Brown, 1985, p. 22).

For example, consider three concepts related to satisfaction: user satisfaction (Wixom and Todd 2005), user information satisfaction (Ives et al. 1983), and end-user computing satisfaction (Doll and Torkzadeh 1988). User satisfaction refers to "the attitude that a user has toward an information system" (Wixom and Todd 2005, p. 87), whereas user information satisfaction is defined as "the extent to which users believe the information system available to them meets their information requirements" (Ives et al. 1983, p. 785). End-user computing satisfaction refers to "the affective attitude towards a specific computer application by someone who interacts with the application directly" (Doll and Torkzadeh 1988, p. 261).

If the three concepts related to satisfaction were the only ones under investigation, they would comprise the content universe. Further, the three concepts share a common skeleton: they all refer to an evaluative response toward some evaluative target (Melone 1990; Muylle et al. 2004). Hence, two facets can be accordingly considered: evaluative response and evaluative target (see Table 1). Evaluative response has two elements or values: attitude and belief. Evaluative target also has two elements: information system and computer application. The three concepts, user satisfaction, user information satisfaction, and end-user computing satisfaction can be contrasted according to the two facets of evaluative response and evaluative target. Notably, there can be other facets not included (e.g., evaluative stakeholder with elements of user, senior manager, developer, vendor, consultant, and so on). We simplified the example for illustration.

\begin{tabular}{|l|l|l|l|}
\hline Facet & User Satisfaction & $\begin{array}{l}\text { User Information } \\
\text { Satisfaction }\end{array}$ & $\begin{array}{l}\text { End-User Computing } \\
\text { Satisfaction }\end{array}$ \\
\hline A: Evaluative Response & $\mathrm{A}_{[1]}$ : Attitude & $\mathrm{A}_{[2]:}$ Belief & $\mathrm{A}_{[1]}$ Attitude \\
\hline B: Evaluative Target & $\mathrm{B}_{[1]]}$ Information System & $\mathrm{B}_{[1]}$ : Information System & $\mathrm{B}_{[2]}$ : Computer Application \\
\hline
\end{tabular}

Table 1. An Example of Facets

Based on the above facets and elements of facets, user satisfaction can be characterized uniquely by a combination of elements, denoted as " $\mathrm{A}_{[1]} \mathrm{B}_{[1]}$ ". Similarly, user information satisfaction and end-user computing satisfaction can be characterized as " $\mathrm{A}_{[2]} \mathrm{B}_{[1]}$ " and " $\mathrm{A}_{[1]} \mathrm{B}_{[2]}$ " respectively.

Guttman (1954a; 1954b) does not explicitly define what a definitional framework is. A definitional framework or more specifically a facet definitional framework must include a full collection of facets and elements of the facets that are used to describe the relationships among concepts in a content universe. Further, when a facet definitional framework is used to describe a content universe, every concept in the content universe should effectively correspond to a unique sequence of elements (e.g., in the prior example "user satisfaction" identified as " $\mathrm{A}_{[1]} \mathrm{B}_{[1]}$ ") (Guttman and Greenbaum 1998). 
In addition to facets and elements of the facets, a definitional framework contains mapping sentences. Argued by Guttman and Greenbaum (1998, p. 16, emphasis added),

A mapping sentence (Shye, 1978, p. 413), is "a verbal statement of the domain and of therange of a mapping, including verbal connectives between facets as in ordinary language." It always consists of two main parts: a formal part made up of the facets and a less formal part comprising the phrases linking the facets together (Shye, 1978, pp. 179-180; Hans, Bernstein, \& Marcus, 1985; Levy, 1990).

An example of a mapping sentence is depicted in Figure 1 (adapted from Guttman and Breenbaum [1998, p. 16]). This mapping sentence summarizes the various possible definitions for intelligence. By selecting from any combination of values in the three facets (e.g., a1, b2, and c1), a specific definition for intelligence can be created (e.g., one concept of intelligence can be defined as "the performance of examinee through oral expression on an item presented orally by the tester with the aid of numerical language, and requiring inference".). There are a total of 27 (3x3x3) possible definitions for intelligence.

Intelligence: The performance of examinee $(x)$

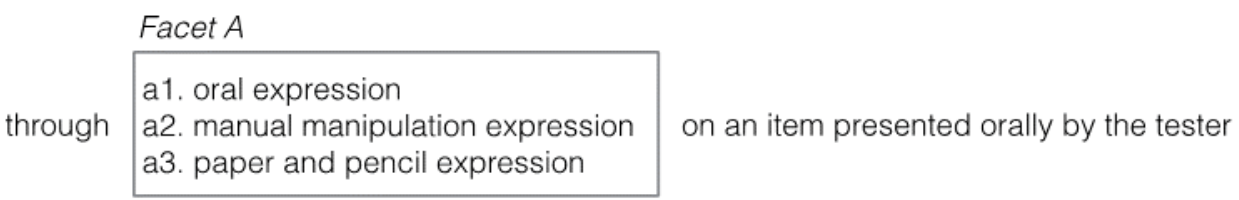

\begin{tabular}{l|l|l|}
\multicolumn{1}{c|}{\begin{tabular}{c}
\multicolumn{1}{c}{ Facet $B$} \\
with the aid of
\end{tabular}} & $\begin{array}{l}\text { Facet } C \\
\text { b1. verbal language } \\
\text { b2. numerical language } \\
\text { b3. geometrical language }\end{array}$ \\
\cline { 2 - 3 } & , and requiring & $\begin{array}{l}\text { c1. inference } \\
\text { c2. application } \\
\text { c3. learning }\end{array}$ \\
\hline
\end{tabular}

Figure 1. An Example of a Mapping Sentence (adapted from Guttman and Breenbaum [1998, p. 16])

\subsection{Facet Theory Methodology}

The original intent of Facet Theory was to provide "a systematic approach to facilitating theory construction, research design, and data analysis for complex studies, that is particularly appropriate to the behavioural and social sciences" (Guttman and Greenbaum 1998, p. 13).

According to Guttman and Greenbaum (1998, p. 16), Guttman's (1954a) "theory” refers to

an hypothesis of a correspondence between a definitional system for a universe of observations, together with a rationale for such an hypothesis.

In other words, "theory" as the term is employed by Guttman, consists primarily of several parts: a definitional framework for a content universe, a set of empirical observations, a hypothetical correspondence between the definitional framework and the set of empirical observations, as well as a rationale underlying the hypothetical correspondence. This definition of "theory" differs from many contemporary views. For example, Sutton and Staw (1995) argued that theory must explain "why variables or constructs come about or why they are connected" (p. 375); for them, a list of variables or a construct alone is not theory (Sutton and Staw 1995).

Typically, the process of Guttman's (1954a) "theory" construction starts with articulating a definitional framework for a content universe and ends with examining the correspondence between the definitional framework and empirical data. In particular, oncea mapping sentence is created, each alternative definition in a mapping sentence can act as a survey scale to measure the corresponding concept. After all the concepts in a content universe are used to 
assess an empirical sample, the ratings of the scales are expected to exhibit a similar pattern of closeness as the concepts in the content universe (Guttman and Greenbaum 1998). If two concepts differ only in one facet out of many, the meanings of the two concepts can be regarded as relatively close (in other words they overlap to a greater extent); in principle, the ratings of the two concepts in an empirical sample would also be close. Facet Analysis is a process in which the researcher examines the correspondence between empirical data and a facet definitional framework, whereas the research design for constructing Guttman's "theory" is called a Facet Design (Shye et al. 1994).

Notably, Guttman's use of the term "Facet Theory" appears to be unique; Facet Theory is neither theory by the definition of Guttman nor by the definitions of others (e.g., Sutton and Staw 1995). We believe that Guttman's "Facet Theory" is better understood as a methodology for developing Guttman's "theory". In contemporary language, Facet Theory can be characterized as a methodology for construct definition, operationalization, and validation. To avoid confusion, we use the term Facet Theory Methodology rather than Facet Theory in the following discussion.

\subsection{Impact of Facet Theory Methodology}

Guttman's (1954a; 1954b) creative work on Facet Theory Methodology (FTM) influenced various disciplines and areas. A main contribution of FTM is to the development of measurement theory in Psychometrics or the methodology of measurement (Guttman 1971); in particular, FTM is sometimes considered to be the forerunner of factor analysis (e.g., Lange 2008; McGrath 1984; Loehlin 1998). In addition, some techniques of FTM (e.g., Facet Analysis techniques) are being used for studying work commitment (Carmeli et al. 2007; Morrow 1983), work values (Elizur 1984), and interpersonal trust (Paul and McDaniel 2004), or in combination with other methods for measurement scale development (Chin et al. 2008) and data analysis (Loehlin 1998). FTM can also provide meaningful interpretation for procedures taken in statistical techniques, such as Multidimensional Scaling (MDS) (Borg and Groenen 2005). According to FTM, the procedures of partitioning MDS space can be interpreted as ensuring each region being representative of a facet element (Borg and Groenen 2005, p. 89). Moreover, FTM can assist with the development of typologies (Lange 2008; Shapira and Zevulun 1979). In particular, types of a typology differ by salient dimensions or facets. FTM gives explicit attention to the most important task in typology development: identifying salient facets for types in a domain of interest and appropriately organizing the facets (McGrath 1968; 1984). Such explicit awareness can facilitate more careful comparison of otherwise identical types (McGrath 1968).

The entirety of FTM is rarely employed and less so more recently. FTM, though claiming strength from comprehensiveness, is criticized for its inattention to a fuller research cycle. The "selection" of related concepts and facets, for example, relies partly on intuition, observation, or "general understanding" of a research domain (Shapira and Zevulun 1979). There is little systematic guidance for this initial selection process, which can, and often does, entail substantial effort and uncertainty (McGrath 1968).

Furthermore, we suspect that the use of FTM is infrequent because of its inattention to links with existing knowledge. Scientific knowledge rarely exists in isolation; it must be a part of the larger scientific enterprise. It appears difficult to position FTM relative to other streams of thoughts. Some procedures in FTM are similar to those in other methods; notions in FTM too sometimes overlap with other contemporary notions (e.g., construct, item, measure, operationalization, etc.). However, there has been little effort to bridge the gap between FTM and contemporary notions and methods. It thus becomes difficult, if not impossible, to evaluate studies that use FTM or identify the core strengths of FTM.

Regardless of these concerns, we argue that the implied logic of FTM may assist in clarifying overlapping concepts. We next discuss what the logic is and explore how we can use it for conceptual clarification. 


\subsection{A Deeper Look at the Logic of FTM}

The measurement and empirical analysis techniques of FTM have been a primary focus in previous literature (McGrath 1968; 1984; Lange 2008). We instead focus on the implied logic of FTM in which we believe the central value lies.

To clarify the implied logic of FTM, a distinction between the "imagery" of FTM and that of other methods and approaches must be made (Shye et al. 1994). FTM conceives concepts, a priori, as closely related to other concepts from the same domain of investigation; a collection of these related concepts constitutes a content universe. FTM assumes that, ontologically, concepts can be likened to "continuous rather than discrete physical bodies" (Shye et al. 1994, p. 40). This ontological view can be contrasted with a relatively "mechanical view" of concepts, which regards concepts as discrete entities; according to this mechanical view, concepts can be independently defined and subsequently be used to investigate causal relationships among them (Shye et al. 1994).

FTM imagery points to the imperative to delineate precisely the conceptual overlap among related concepts, prior to examining causal links to and from them. Further, an implicit logic based on theimagery can be used for clarification (McGrath 1968); this logic formally describes the structure and the state of a classification system that ought to clarify related concepts to the extent possible.

McGrath (1968, p. 192 - 197) succinctly summarized the implied logic with a set of principles. We thus adapted McGrath's (1968) principles to explicate the logic of FTM. Note that there are alternative terms used in the literature. For instance, McGrath (1968) and others employ "property" and "dimension" as synonymous with "facet" and refer to concepts as "objects" and elements of facets as "values" and "categories". We replaced McGrath's (1968) terms with the terms that are more familiar to the general IS community. The adapted principles are outlined as follows (MoGrath 1968, pp. 192 - 197).

P1: Concepts in a content universe should be specified in terms of all relevant facets.

P2: The facets, collectively, should be logically exhaustive of the content universe.

P3: The logical relationships among facets should be specified; independence among facets is preferred.

P4: Each facet should be analysed into a set of collectively exhaustive elements.

P5: Each facet should be analysed into a set of mutually exclusive elements.

P6: The logical relationships among elements of a facet should be specified.

P7: Therelationships among the concepts defined according to the facets and the elements of facets should correspond to the focal phenomenon.

This set of principles centres on clarifying overlapping concepts, the practice of which can be contrasted with a nomological view that emphasizes causal relationships among constructs. By recognizing a continuum of the similarity in the meanings of constructs, the principles encourage conceptual clarification without relying on causal links. The principles suggest any construct ought to be conceptualized based on the meanings of other related constructs. If the relations between a focal construct and other related constructs fulfil the requirements set by the principles, the conceptualization of the focal construct is considered to be clear.

Positivists and constructivists might have distinctive expectations about construct clarity. For instance, positivist researchers might insist on a construct's role in predicting empirical observables, and therefore might support the view that clear constructs must also enable easy operationalization across various contexts. In contrast, constructivist researchers might develop constructs merely to label particular phenomena within a context (i.e., not requiring that the constructs can be easily operationalized within other contexts) and hence, might not hold the same view on construct clarity as positivist researchers. Consistent with Suddaby (2010), we hold a relatively neutral philosophical stance, avoiding aligning with either view. 
We believe our ideas presented may have pragmatic value for both (the relevance of the neutral stance is further amplified in the last principle illustrated in the subsequent section).

\subsection{Illustration of the Principles}

Drawing from our previous example of satisfaction (Table 1), we illustrate in detail the set of principles.

Principle 1: Concepts in a content universe should be specified in terms of all relevant facets.

It is important to ensure that every concept within a content universe is specified by all relevant facets. In the illustrative example, each of user satisfaction, user information satisfaction, and end-user computing satisfaction must be specified by all the two facets of evaluative response and evaluative target. In practice, this step is often done through systematic search and analysis of the literature. For example, Li and Belkin (2008, pp. 1833 - 1835) carefully searched all the relevant facets for the concepts of task; they begin with an initial identification of facets used explicitly or implicitly by extant literature and proceed further with categorizing facets and merging redundant facets.

Principle 2: The facets, collectively, should be logically exhaustive of the content universe.

The exhaustiveness criterion for facets is met if and only if including an additional facet will not achieve any further distinction of concepts in the content universe. This means the criterion of exhaustiveness can be a stopping point for searching for new facets. Assume we did not define evaluative target facet in the illustrative example; user satisfaction and end-user computing satisfaction are characterized as the same by existing facets. By defining the additional facet of evaluative target, user satisfaction and end-user computing satisfaction can be further distinguished. We can therefore conclude that the set of facets that contains only evaluative response is not exhaustive for the content universe consisting of these three concepts. In contrast, both facets of evaluative response and evaluative target are exhaustive, because all three concepts in this content universe are already distinguished from each other; any attempt to include more facets would not achieve further distinction.

Principle 3: Thelogical relationships among facets should be specified; independence among facets is preferred.

Relationships among facets must be clearly specified. It is preferred that facets are logically independent of each other; such a group of facets is most efficient (McGrath 1968). Independence means the determination of an element in any facet will not affect the determination of an element in another facet. If the independence criterion were violated, there would exist so-called "null cells" (in a cross-reference of all facets in multidimensional space) that would never be referenced (McGrath 1968).

Again, using the illustrative example, assume we have defined an additional facet, called theoretical level, characterizing the level of theory to which the generalization of the concept is manifested (Kozlowski and Klein 2000). We further assume this facet has two elements, individual level and organizational level. This facet is not independent of the evaluative response facet, because when attitude is used to characterize concepts, by implication the individual level will always be used. In this example, the combination of attitude and organizational level will thus never be used to characterize any existing or potential concepts (here, we assume a collective's attitude is no longer an attitude, but another type of evaluative response). The inclusion of theoretical level as a new facet will thus result in possiblenull cells. Null cells indicate inefficient use of facets and are undesirable. Parsimony or simplicity can be gained from efficient usage of facets.

Principle 4: Each facet should be analysed into a set of collectively exhaustive elements.

Elements within a facet should also be exhaustive. This exhaustiveness criterion for elements is met if and only if each concept in the content universe can be characterized by at least one element in each facet. Consider another variation of the illustrative example, where the evaluative response facet has only the one element, attitude. In such a case, the set of elements 
for evaluative response facet is not exhaustive, because user information satisfaction cannot be characterized by any element in the evaluative response facet. In contrast, it is exhaustive only when evaluative response facet includes both elements of attitude and belief.

Principle 5: Each facet should be analysed into a set of mutually exclusive elements.

In addition to exhaustiveness, the elements in any facet must be mutually exclusive, such that each concept in a content universe can be characterized by only one element of any given facet. For example, all three concepts of user satisfaction, user information satisfaction, and enduser computing satisfaction, can be exclusively characterized by either attitude or belief of evaluative response facet (never both). The elements in evaluative response facet are thus mutually exclusive.

Principle 6: The logical relationships among elements of a facet should be specified.

Relationships among elements of a facet must be clearly specified. There are several possibilities. For the evaluative target facet in the illustrative example, a hierarchical order of elements could exist, such as computer application and information system ranked from lower to higher level of analysis. Alternatively, the relationship between these two elements could be specified as inclusive - information system consists of computer application and other parts. All others being equal, any selection for the relationship among elements must be justifiable to the extent the purpose of the research is satisfied.

Principle 7: The relationships among the concepts defined according to the facets and the elements of facets should correspond to the focal phenomenon.

How can we know or assess the usefulness of facets and elements used? McGrath (1968) suggested "the principle of concordance or contiguity" for evaluating the usefulness of facets and elements. He (McGrath 1968, p. 197) argued,

Regardless of the purpose of the system or the nature of the objects to be classified, though, it seems clear that the major aim of any a priori classification ought to be to order the objects in terms of their logical properties in such a way as to be predictive of their ordering on (meaningful) empirical properties.

Concepts that are theorized to be alike should also be empirically alike (McGrath 1968). In the illustrative example, user satisfaction and end-user computing satisfaction are different on the evaluative target facet, whereas user information satisfaction and end-user computing satisfaction are different on both the evaluative response and the evaluative target facets. Enduser computing satisfaction can be interpreted as more "like" user satisfaction than user information satisfaction (by assuming equal contribution of every facet to "likeness"). The relationships among concepts or the "likeness" should be expected from empirical observations. Note that there might be other ways to operationalize "likeness".

We adapted McGrath's (1968) "principle of concordance or contiguity" to accommodate diverse views. In particular, we believe that it is unnecessary to constrain the target concepts to those emphasizing empirical prediction; instead, for concepts that do not emphasize strong empirical prediction or "mirroring reality" (e.g., metaphysical or linguistic concepts such as "dilemma", "paradox", "system", "adaptation", and "punctuated equilibrium"), the researcher can establish the correspondence between a definitional framework and an (shared or not shared) interpreted or constructed phenomenon. The usefulness of facets and elements can be verified through the process in which the concepts are continuously used by a group of researchers.

\section{Discussion}

The logic of FTM offers guidance on clarifying concepts. Usually, first and foremost in clarification, is the need to explore and specify relevant criteria: To what extent can concepts be compared and contrasted? On what bases should comparison and contrast be achieved? In 
response, the logic visualizes how concepts ought to be related and encourages continuous efforts toward the fulfilment of the vision.

Inquiries into construct clarity must rely on a fundamental belief system. Kaplan (1964) observed an infinite regression that pervades scientific investigation. Answering one question can stimulate further inquiries into the assumptions taken in addressing the first question; it is crucial that we, at some point, stop asking "why" but instead believe certain assumptions. When clarifying one focal concept, we certainly could delve into more than one metatheoretical level, through, for example, treating facets and elements of the facets as unknown concepts and clarify their meanings before applying them to the focal concept. Such regressive clarification can go through several iterations. To avoid endless clarification, we must, however, at some point, regard the meanings of some concepts (or meta-theoretical concepts) as self-evident (e.g., the meanings of evaluative target and response in our prior illustrative example). From a more pragmatic perspective, Van de Ven (2007, p. 117) commented,

Thus, even though the objective of semantic and constitutive definitions is to clearly specify the meaning and usage of terms, they always remain vague in some respects. Lines are and must be drawn for the pragmatic purpose of being sufficient to address the problem. [...] Tolerance of ambiguity is important for scientific inquiry.

A caveat should be noted. The prior illustrative example of satisfaction might unwittingly give the impression that only linguistic interpretation of a concept is emphasized. We note this impression is far from our intent. Specifically, it is unnecessarily restrictive in FTM to require that facets and elements must come from a linguistic or semantic definition of a concept, or, conversely, that a definition of a concept must includeall facets and elements of the facets. Put differently, the proposed principles are not limited to a concept's linguistic meaning, but also apply to its underlying, implied properties; facets and elements can be and often are absent in a definition (e.g., level of analysis).

\section{Limitation and Future Research}

This research is exploratory in nature and entails limitations. This research analysed construct clarity mostly by focusing on a construct's relationships with extant related constructs. The complications of isolating the issue may need to be considered. Given the existence of other aspects of construct clarity, it remains less clear how the whole, rather than the sum of the differing aspects, of construct clarity can be achieved and to what extent these different aspects of construct clarity can be separately achieved. Furthermore, this research emphasized metatheoretical principles. Future research may consider specific strategies for using the metatheoretical principles in conceptualization.

\section{Conclusion}

This paper was initially motivated by the central importance of conceptualization and associated issues with research comparability and cumulative contribution to knowledge. Our reference to the IT value literature is used to illustrate the relevance of construct clarity and to enliven discussion of the issue within a broader IS community. We put forward the view that construct clarity is essential in conceptualization, and offered a meta-theoretical account of conceptualization that might help achieve construct clarity. This account explores what a clearly conceptualized construct ought to be. We hope these considerations can guide conceptualization practice and advance methodological theory of conceptualization. A related aim is to introduce Facet Theory to the IS research community and encourage its exploitation. We believe that the perspective taken in Facet Theory is largely absent from IS research and that attention to Facet Theory could offer much unexplored potential.

\section{References}

Borg, I., and Groenen, P. J. 2005. "MDS and Facet Theory," in Modern Multidimensional Scaling: Theory and Applications, Springer, pp. 87- 109. 
Burton-J ones, A., and Straub, D. W. 2006. "Reconceptualizing System Usage: an Approach and Empirical Test," Information Systems Research (17:3), pp. 228- 246.

Carmeli, A., Elizur, D., and Yaniv, E. 2007. "The Theory of Work Commitment: a Facet Analysis," Personnel Review (36:4), pp. 638- 649.

Carr, N. G. 2003. “IT Doesn't Matter,” Harvard Business Review (81:5), pp. 41- 49.

Chan, Y. E. 2000. "IT Value: the Great Divide Between Qualitative and Quantitative and Individual and Organizational Measures," Journal of Management Information Systems (16:4), pp. 225- 261.

Chin, W. W., Johnson, N., and Schwarz, A. 2008. "A Fast Form Approach to Measuring Technology Acceptance and Other Constructs," MIS Quarterly (32:4), pp. 687- 703.

Cook, T. D., and Campbell, D. T. 1979. Quasi-Experimentation: Design and Analysis Issues for Field Settings, Boston: Houghton Mifflin.

Cronbach, L. J., and Meehl, P. E. 1955. "Construct Validity in Psychological Tests," Psychological Bulletin (52:4), pp. 281- 302.

Davis, F. D. 1989. "Perceived Usefulness, Perceived Ease of Use, and User Acceptance of Information Technology," MIS Quarterly (13:3), pp. 319- 340.

Dedrick, J ., Gurbaxani, V., and Kraemer, K. L. 2003. "Information Technology and Economic Performance: a Critical Review of the Empirical Evidence," ACM Computing Surveys (35:1), pp. 1- 28.

DeLone, W. H., and McLean, E. R. 1992. “Information Systems Success: the Quest for the Dependent Variable," Information Systems Research (3:1), pp. 60- 95.

DeLone, W. H., and McLean, E. R. 2003. "The DeLone and McLean Model of Information Systems Success: a Ten-Year Update," J ournal of Management Information Systems (19:4), pp. 9-30.

Doll, W. J ., and Torkzadeh, G. 1988. “The Measurement of End-User Computing Satisfaction,” MIS Quarterly (12:2), pp. 259- 274.

Elizur, D. 1984. "Facets of Work Values: a Structural Analysis of Work Outcomes," J ournal of Applied Psychology (69:3), pp. 379- 389.

Gable, G. G., Sedera, D., and Chan, T. 2008. "Re-Conceptualizing Information System Success: the IS-Impact Measurement Model," Journal of the Association for Information Systems (9:7), pp. 377-408.

Grover, V., J eong, S. R., and Segars, A. H. 1996. "Information Systems Effectiveness: the Construct Space and Patters of Application," Information \& Management (31:4), pp. 177- 191

Guttman, L. 1954a. “An Outline of Some New Methodology for Social Research,” Public Opinion Quarterly (18:4), pp. 395- 404.

Guttman, L. 1954b. "A New Approach to Factor Analysis: the Radex," in Mathematical Thinking in the Social Sciences P. F. Lazarsfeld (ed.), New York, NY, US: Free Press, pp. 258-348.

Guttman, L. 1971. “Measurement as Structural Theory,” Psychometrika (36:4), pp. 329- 347.

Guttman, R., and Greenbaum, C. W. 1998. "Facet Theory: Its Development and Current Status," European Psychologist (3:1), pp. 13- 36.

Hirsch, P. M., and Levin, D. Z. 1999. “Umbrella Advocates Versus Validity Police: a Life-Cycle Model,” Organization Science (10:2), pp. 199-212. 
Hitt, L. M., Wu, D. J., and Zhou, X. 2002. "Investment in Enterprise Resource Planning: Business Impact and Productivity Measures," Journal of Management Information Systems (19:1), pp. 71- 98.

Im, K. S., Dow, K. E., and Grover, V. 2001. "Research Report: a Reexamination of IT Investment and the Market Value of the Firm-an Event Study Methodology," Information Systems Research (12:1), pp. 103- 117.

Ives, B., Olson, M. H., and Baroudi, J. J. 1983. "The Measurement of User Information Satisfaction," Communications of the ACM (26:10), pp. 785- 793.

Klein, H. J., and Delery, J. E. 2012. "Construct Clarity in Human Resource Management Research: Introduction to the Special Issue," Human Resource Management Review (22:2, SI), pp. 57- 61.

Kohli, R., and Devaraj, S. 2003. "Measuring Information Technology Payoff: a Meta-Analysis of Structural Variables in Firm-Level Empirical Research," Information Systems Research (14:2), pp. 127- 145.

Kohli, R., and Grover, V. 2008. "Business Value of IT: an Essay on Expanding Research Directions to Keep Up with the Times," J ournal of the Association for Information Systems (9:1), pp. 23-39.

Kozlowski, S. W. J., and Klein, K. J . 2000. "A Multilevel Approach to Theory and Research in Organizations: Contextual, Temporal, and Emergent Processes," in Multilevel Theory, Research, and Methods in OrganizationsK. J. Klein and S. W. J . Kozlowski (eds.), San Francisco: J ossey-Bass Inc., pp. 3-90.

Lange, D. 2008. "A Multidimensional Conceptualization of Organizational Corruption Control," Academy of Management Review (33:3), pp. 710- 729.

Li, Y., and Belkin, N. J. 2008. "A Faceted Approach to Conceptualizing Tasks in Information Seeking," Information Processing \& Management (44:6), pp. 1822- 1837.

Locke, E. A. 2012. “Construct Validity vs. Concept Validity,” Human Resource Management Review (22:2), pp. 146- 148.

Loehlin, J . C. 1998. Latent Variable Models: an Introduction to Factor, Path, and Structural Analysis, Lawrence Erlbaum Associates Publishers.

MacKenzie, S. B., Podsakoff, P. M., and Podsakoff, N. P. 2011. “Construct Measurement and Validation Procedures in MIS and Behavioral Research: Integrating New and Existing Techniques," MIS Quarterly (35:2), pp. 293- 334.

Markus, M. L., and Saunders, C. 2007. "Editor's Comments: Looking for a Few Good Concepts. . and Theories. . for the Information Systems Field," MIS Quarterly (31:1), pp. iii-vi.

McGrath, J. E. 1968. "A Multi-Facet Approach to Classification of Individual Group and Organizational Concepts," in People, Groups, and Organizations, New York: Teachers College Press, pp. 191- 215.

McGrath, J . E. 1984. Groups: Interaction and Performance, Prentice-Hall Englewood Cliffs, NJ.

Melone, N. P. 1990. "A Theoretical Assessment of the User-Satisfaction Construct in Information Systems Research," Management Science (36:1), pp. 76- 91.

Melville, N., Kraemer, K., and Gurbaxani, V. 2004. "Review: Information Technology and Organizational Performance: an Integrative Model of IT Business Value," MIS Quarterly (28:2), pp. 283- 322.

Morrow, P. C. 1983. "Concept Redundancy in Organizational Research: the Case of Work Commitment," Academy of Management Review (8:3), pp. 486- 500. 
Murphy, K. E., and Simon, S. J. 2002. "Intangible Benefits Valuation in ERP Projects," Information Systems J ournal (12:4), pp. 301- 320.

Muylle, S., Moenaert, R., and Despontin, M. 2004. "The Conceptualization and Empirical Validation of Web Site User Satisfaction," Information \& Management (41:5), pp. 543560.

Nunnally, J . C., and Bernstein, I. H. 1994. Psychological Theory, NewYork: MoGraw-Hill.

Orlikowski, W., and Iacono, C. S. 2001. “Desperately Seeking the 'IT' in IT Research-a Call to Theorizing the IT Artifact," Information Systems Research (12:2), pp. 121- 134.

Osigweh Yg, C. A. B. 1989. “Concept Fallibility in Organizational Science,” Academy of Management Review (14:4), pp. 579- 594.

Paul, D. L., and McDaniel, R. R., Jr. 2004. "A Field Study of the Effect of Interpersonal Trust on Virtual Collaborative Relationship Performance," MIS Quarterly (28:2), pp. 183- 227.

Petter, S., DeLone, W., and McLean, E. 2008. "Measuring Information Systems Success: Models, Dimensions, Measures, and Interrelationships," European J ournal of Information Systems (17:3), pp. 236- 263.

Petter, S., DeLone, W., and McLean, E. R. 2012. "The Past, Present, and Future of 'TS Success'," J ournal of the Association for Information Systems (13:5), pp. 341- 362.

Petter, S., Straub, D., and Rai, A. 2007. "Specifying Formative Constructs in Information Systems Research,” MIS Quarterly (31:4), pp. 623- 656.

Rai, A., Lang, S. S., and Welker, R. B. 2002. "Assessing the Validity of IS Success Models: an Empirical Test and Theoretical Analysis," Information Systems Research (13:1), pp. 5069.

Rai, A., Patnayakuni, R., and Patnayakuni, N. 1997. "Technology Investment and Business Performance," Communications of the ACM (40:7), pp. 89- 97.

Schryen, G. 2012. "Revisiting IS Business Value Research: What We Already Know, What We Still Need to Know, and How We Can Get There," European J ournal of Information Systems (22:2), pp. 139- 169.

Schwab, D. P. 1980. "Construct Validity in Organizational Behavior," Research in Organizational Behavior (B. M. Staw and L. L. Cummings, eds.) (2), pp. 3- 43.

Seddon, P. B., Staples, S., Patnayakuni, R., and Boutell, M. 1999. "Dimensions of Information Systems Success," Communications of the Association for Information Systems (2:20), pp. 1-61.

Shang, S., and Seddon, P. B. 2002. "Assessing and Managing the Benefits of Enterprise Systems: the Business Manager's Perspective," Information Systems J ournal (12:4), pp. 271- 299.

Shapira, Z., and Zevulun, E. 1979. "On the Use of Facet Analysis in Organizational Behavior Research: Some Conceptual Considerations and an Example," Organizational Behavior and Human Performance (23:3), pp. 411- 428.

Shye, S., Elizur, D., and Hoffman, M. 1994. Introduction to Facet Theory: Content Design and Intrinsic Data Analysis in Behavioral Research (S. Shye, D. Elizur, and M. Hoffman, eds.), Thousand Oaks, CA, US: SAGE Publications, Inc.

Skilton, P. F. 2011. “Getting the Reader to 'I Get It!': Clarification, Differentiation and Illustration," J ournal of Supply Chain Management (47:2), pp. 22- 28.

Straub, D., Boudreau, M.-C., and Gefen, D. 2004. "Validation Guidelines for IS Positivist Research," Communications of the Association for Information Systems (13:1), p. 24. 
Suddaby, R. 2010. "Editor's Comments: Construct Clarity in Theories of Management and Organization," Academy of Management Review (35:3), pp. 346- 357.

Sutton, R. I., and Staw, B. M. 1995. "What Theory Is Not," Administrative Science Quarterly (40:3), pp. 371- 384.

Van de Ven, A. H. 2007. "Building a Theory," in Engaged Scholarship a Guide for Organizational and Social Research A. H. Van de Ven (ed.), Oxford: Oxford University Press.

Wade, M., and Hulland, J . 2004. "Review: the Resource-Based View and Information Systems Research: Review, Extension, and Suggestions for Future Research," MIS Quarterly (28:1), pp. 107- 142.

Weber, R. 2012. "Evaluating and Developing Theories in the Information Systems Discipline," J ournal of the Association for Information Systems (13:1), pp. 1- 30.

Wixom, B. H., and Todd, P. A. 2005. "A Theoretical Integration of User Satisfaction and Technology Acceptance," Information Systems Research (16:1), pp. 85- 102.

Yaniv, E. 2011. "Construct Clarity in Theories of Management and Organization," Academy of Management Review (36:3), pp. 590- 592.

Copyright: (c) 2016 Zhang, Gable, Rai. This is an open-access article distributed under the terms of the Creative Commons Attribution-NonCommercial 3.0 Australia License, which permits non-commercial use, distribution, and reproduction in any medium, provided the original author and AJ IS are credited.

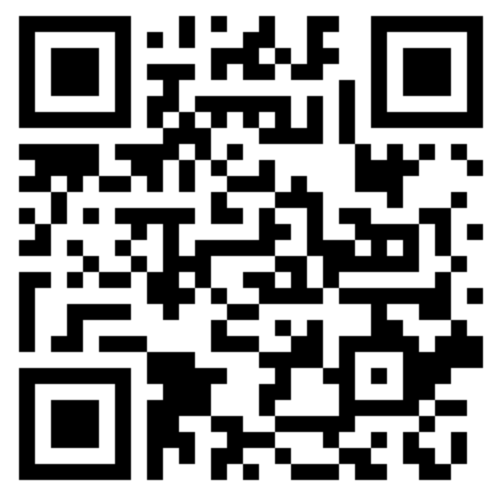

